\title{
Clonal relationship among invasive and non-invasive strains of enteroinvasive Escherichia coli serogroups
}

\author{
Marina B. Martinez ${ }^{\mathrm{a}, *}$, Thomas S. Whittan ${ }^{\mathrm{b}}$, Elizabeth A. McGraw ${ }^{\mathrm{b}}$, \\ Josias Rodrigues ${ }^{\mathrm{c}}$, Luiz R. Trabulsi ${ }^{\mathrm{d}}$ \\ a Faculdade de Ciencias Farmaceuticas, Departamento de Analises Clinicas e Toxicologicas, Universidade de Sao Paulo, \\ Av. Prof. Lineu Prestes 580, Sao Paulo-SP, 05508-900 Brazil \\ ${ }^{\mathrm{b}}$ Institute of Molecular Evolutionary Genetics, Department of Biology, The Pennsylvania State University, University Park, PA 16802, USA

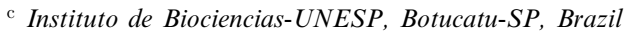 \\ d Instituto Butantan, Sao Paulo-SP, Brazil
}

Received 3 November 1998; received in revised form 5 January 1999; accepted 5 January 1999

\begin{abstract}
The genetic relatedness among 96 invasive Escherichia coli belonging to several serogroups and 13 non-invasive of several serotypes that share the same $\mathrm{O}$ antigen was investigated by multilocus enzyme electrophoresis analysis. The invasive strains were isolated in different parts of the world and most of them recovered from dysentery. Twenty-nine electrophoretic types were distinguished and the most invasive strains were found to belong to two major lineages. These results suggested that the invasive ability in these strains has evolved in divergent chromosomal backgrounds, presumably through the horizontal spread of plasmid-borne invasion genes. The maintenance of invasive phenotypes in separate lineages suggests that this ability confers a selective advantage to invasive strains. (c) 1999 Published by Elsevier Science B.V. All rights reserved.
\end{abstract}

Keywords: Clonal relationship; Multilocus enzyme electrophoresis; Genetic polymorphism; Enteroinvasive Escherichia coli

\section{Introduction}

Some Escherichia coli strains are positive in the Serény test for invasiveness and cause a Shigellalike illness in humans, both children and adults [16]. The ability to invade colonic epithelial cells is mediated by a large plasmid encoding genetic determinants required for invasion [1,3]. These E. coli strains are known as enteroinvasive $E$. coli (EIEC)

\footnotetext{
* Corresponding author. Tel.: +55 (11) 818-3636; Fax: +55 (11) 813-2197; E-mail: mbmartin@usp.br
}

and this name has been universally accepted [7]. The EIEC corresponds to bioserotypes found in a dozen of $E$. coli serogroups [8]. Interestingly, some of these $\mathrm{O}$ antigens are identical or similar to Shigella $\mathrm{O}$ antigens [7].

The role played by EIEC in endemic diarrheal disease has not been investigated extensively. However, some studies indicated that these bacteria can be isolated with relatively high frequency depending on the population investigated. In the city of Sao Paulo, in Brazil for example, EIEC has been found in $5-7 \%$ of children living in medium-income families 
and in $20 \%$ of children who live in a slum, in the outskirts of the city. Both groups studied involved children older than 2-years-old, and they all showed acute diarrhea [8]. A similar frequency to that of Sao Paulo, has been reported by Echeverria et al. in Bangkok [9]. Outbreaks of food-borne infections due to EIEC have also been reported elsewhere [4].

Studies carried out on the biochemical characteristics of EIEC strains have shown that these bacteria do not decarboxylase lysine and except for a few serotypes, most strains are not motile. Strains that possess EIEC $\mathrm{O}$ antigens but decarboxylase lysine are always Sereny negative. These characteristics suggest that EIEC strains correspond to typical $E$. coli bioserotypes [10,11].

Multilocus enzyme electrophoresis (MLEE), which has long been a standard method in eukaryotic population genetics and systematics, has been used in studies to estimate the genetic diversity and structure in natural populations of a variety of species of bacteria. This research has established basic population genetic frameworks for the analysis of variation in serotypes and other phenotypic characters and has provided extensive data for systematics and useful marker systems for epidemiology [12].

In the present study, we determined the genetic relationship among invasive strains in an effort to learn more about the evolution of the invasive phenotype. We examined isolates representing ten EIEC serogroups commonly recovered from dysentery and characterized chromosomal backgrounds by MLEE. We compared the MLEE profile of EIEC strains with that of non-invasive, motile strains belonging to the same serogroups.

\section{Materials and methods}

\subsection{Bacterial isolates}

A total of 96 enteroinvasive and 13 non-enteroinvasive $E$. coli strains isolated from patients with diarrhea from different countries, between 1965 and 1988 were studied in this study. The strains from Brazil were collected from different cities. A total of 10 EIEC serotypes were studied, $98 \%$ were collected from cases of diarrhea in humans, $68 \%$ of the isolates were from Brazil, and remaining strains were isolated in different countries. The biochemical profiles and the serogroups of all strains were performed by standard methods [7]. Invasiveness was assessed by the Sereny test [13]. The number of invasive strains and their $\mathrm{O}$ and flagellar antigens of isolates are listed in Table 1.

\subsection{Multilocus enzyme electrophoresis.}

Genetic variation was analyzed by horizontal starch gel electrophoresis to detect polymorphisms for 20 enzyme loci, as previously described [14]. Electromorphs were compared to standard mobility markers and assigned mobility ranks by the rate of migration. Isolates lacking a particular enzyme activity were designated null for that particular locus. Each distinctive array of alleles was designated an electrophoretic type or ET [14]. The allelic arrays for the 20 loci defining ETs are listed in Table 2.

\subsection{Phylogenetic analysis}

Phylogenetic relationships between ETs were determined based on a matrix of genetic distances between all pairs constructed by comparisons of the allelic arrays. The neighbor-joining algorithm was used to constructed the dendrogram with the program MEGA [15,16]. The resulting phylogenetic tree produced is a representation of the genetic divergence observed in the different in the chromosomal backgrounds.

\section{Results}

\subsection{Enzyme polymorphism electrophoretic groups and clonal groups}

All 109 isolates were examined for allelic variation at 20 enzyme loci by MLEE. Fifteen of 20 enzymes loci were polymorphic, with an average of three alleles per locus. Comparison of the allele profiles of strains revealed 29 electrophoretic types (ETs), 19 of which included enteroinvasive strains (Tables 1 and 2). Among the total 29 ETs, 15 were represented by multiple isolates recovered from unrelated hosts at 
Table 1

Electrophoretic type (ET), serotype, Séreny test and lysine decarboxylase of EIEC strains

\begin{tabular}{|c|c|c|c|c|c|c|}
\hline ET & Serotype & $\begin{array}{l}\text { No. of } \\
\text { strains }\end{array}$ & Serény test & $\begin{array}{l}\text { Lysine } \\
\text { decarboxylase }\end{array}$ & Period of isolation & Country of origin \\
\hline 1 & $\mathrm{O} 28 \mathrm{ac}: \mathrm{H}^{+}$ & 3 & - & + & $1971-1981$ & Brazil/Japan \\
\hline 3 & $\mathrm{O} 136: \mathrm{H} 25$ & 1 & - & + & 1980 & Japan \\
\hline 4 & $\mathrm{O} 136: \mathrm{H} 40$ & 1 & - & + & 1982 & Brazil \\
\hline 5 & O124:H19 & 1 & - & + & 1982 & Brazil \\
\hline 7 & O136:NM & 1 & + & - & 1985 & Brazil \\
\hline 8 & $\mathrm{O} 29: \mathrm{H} 10$ & 1 & - & + & 1978 & Brazil \\
\hline 9 & $\mathrm{O} 29: \mathrm{H}^{+}$ & 1 & - & + & 1984 & Mexico \\
\hline 9 & O143:NM & 1 & + & - & 1979 & Brazil \\
\hline 10 & O143:NM & 1 & + & - & 1985 & Brazil \\
\hline 14 & O28ac:NM & $3^{\mathrm{a}}$ & - & - & & Japan/USA \\
\hline \multirow[t]{3}{*}{15} & O28ac:NM & 4 & + & - & $1978-1982$ & Brazil/Chile \\
\hline & & & & & & Japan/USA \\
\hline & NT & 1 & + & - & 1981 & USA \\
\hline 16 & O164:NM & 3 & + & - & $1980-1985$ & Brazil/Japan \\
\hline \multirow[t]{3}{*}{17} & O136:NM & 11 & + & - & $1968-1983$ & Brazil/Japan \\
\hline & & & & & & Hungary \\
\hline & & & & & & Bangladesh \\
\hline 18 & $\mathrm{O} 29: \mathrm{NM}$ & 6 & + & - & 1976-1982 & Brazil/Chile \\
\hline & & & & & & USA \\
\hline 19 & O143:NM & 6 & + & - & 1965-1982 & Brazil/Chile \\
\hline 25 & O124:NM & 16 & + & - & 1965-1988 & Brazil/Japan \\
\hline 25 & O124:H30 & 3 & + & - & & Hungary/USA \\
\hline 26 & O164:NM & 1 & + & - & 1985 & Brazil \\
\hline 27 & O124:NM & $1^{\mathrm{b}}$ & - & - & 1985 & Brazil \\
\hline 28 & 0124:H19 & 1 & - & + & 1977 & Brazil \\
\hline 29 & $\mathrm{O} 143: \mathrm{H}^{+}$ & 1 & - & + & 1979 & Brazil \\
\hline
\end{tabular}

${ }^{\mathrm{a}}$ One strain isolated from cheese.

${ }^{\mathrm{b}}$ Isolated from water.

different times and different countries. Thus, these ETs were considered to mark widespread bacterial clones. In all but 4 cases, the isolates of the same ET belonged to the same serotype. The exceptions were: (1) ET 7, which comprised two invasive isolates of $\mathrm{O} 124: \mathrm{H} 7$ serotype and a non-motile
O136:NM strain; (2) ET 9 included a non-invasive strain serotype O29 motile and an invasive O143:NM strain; (3) ET 15 included an O28:NM and an $\mathrm{O}$ non-typable strain, both of which were non-motile and invasive, and (4) ET 25, for which most of the $\mathrm{O} 124$ invasive isolates were non-motile, 


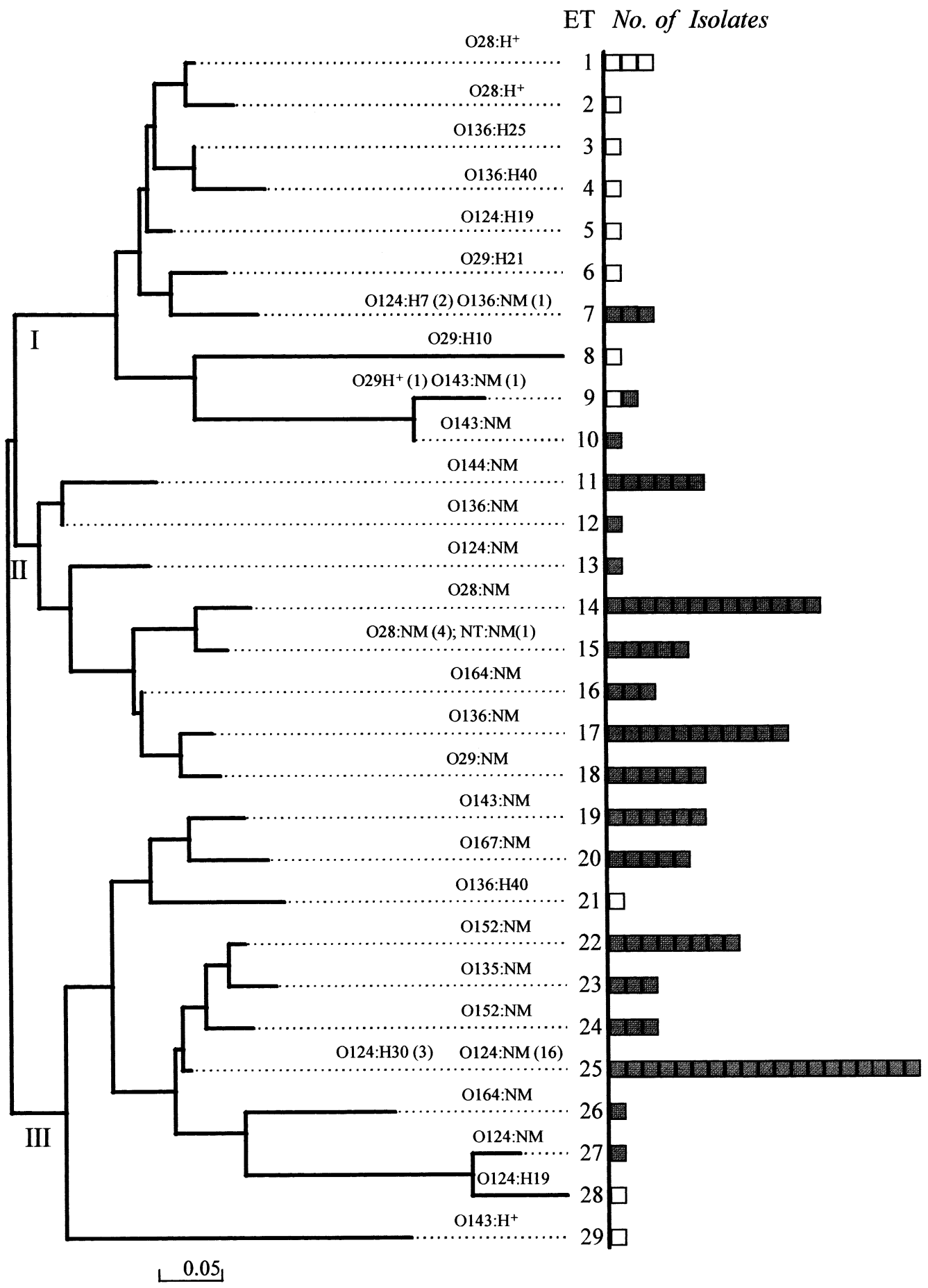

Genetic distance

Fig. 1. Dendrogram of genetic relationship of 29 ETs of EIEC and non-EIEC strains. Genetic distance is measured in terms of detectable codon differences per enzyme locus. $\square$, EIEC strains; $\square$, non-EIEC strains. 
Table 2

Allele combination for 20 polymorphic enzymes that define 19 electrophoretic types (ETs) among enteroinvasive $E$. coli serotypes

\begin{tabular}{|c|c|c|c|c|c|c|c|c|c|c|c|c|c|c|c|c|c|c|c|c|c|c|}
\hline ET & $\begin{array}{l}\text { No. } \\
\text { of } \\
\text { strains }\end{array}$ & Serotype & PGI & I IDH & $\mathrm{ACO}$ & G3P & PE2 & $\mathrm{AK}$ & MDH & PGD & M1P & GOT & BGA & $\mathrm{ADH}$ & MPI & G6P & IPO & CAK & NSP & TDH & SKD & GLU \\
\hline 1 & 3 & 028:H+ & 6 & 5 & 6 & 4 & 5 & 2 & 4 & 62 & 8 & 6 & 5 & 6 & 102 & 4 & 4 & 4 & 2 & 4 & 8 & 2 \\
\hline 2 & 1 & $\mathrm{O} 28: \mathrm{H}+$ & 6 & 5 & 6 & 4 & 5 & 2 & 4 & 62 & 8 & 6 & 6 & 0 & 102 & 4 & 4 & 4 & 2 & 4 & 8 & 2 \\
\hline 3 & 1 & $\mathrm{O} 136: \mathrm{H} 25$ & 6 & 5 & 6 & 4 & 5 & 2 & 4 & 6 & 8 & 6 & 5 & 0 & 102 & 4 & 4 & 4 & 2 & 4 & 8 & 2 \\
\hline 4 & 1 & $\mathrm{O} 136: \mathrm{H} 40$ & 6 & 5 & 6 & 4 & 5 & 2 & 4 & 6 & 8 & 4 & 5 & 6 & 102 & 4 & 4 & 4 & 2 & 4 & 8 & 2 \\
\hline 5 & 1 & O124:H19 & 6 & 5 & 6 & 4 & 5 & 2 & 4 & 8 & 8 & 6 & 5 & 0 & 102 & 4 & 4 & 4 & 2 & 4 & 8 & 2 \\
\hline 6 & 1 & O29:H21 & 6 & 5 & 6 & 4 & 5 & 1 & 4 & 13 & 8 & 6 & 5 & 0 & 102 & 4 & 4 & 4 & 2 & 4 & 8 & 2 \\
\hline 7 & 2 & $\mathrm{O} 124: \mathrm{H} 7$ & 6 & 5 & 6 & 4 & 5 & 1 & 4 & 8 & 8 & 6 & 0 & 6 & 102 & 4 & 4 & 4 & 2 & 4 & 8 & 2 \\
\hline & 1 & $\mathrm{O} 136: \mathrm{NM}$ & 6 & 5 & 6 & 4 & 5 & 1 & 4 & 8 & 8 & 6 & 0 & 6 & 102 & 4 & 4 & 4 & 2 & 4 & 8 & 2 \\
\hline 8 & 1 & O29:H10 & 6 & 7 & 6 & 4 & 5 & 1 & 4 & 14 & 8 & 6 & 74 & 0 & 2 & 4 & 4 & 4 & 2 & 4 & 8 & 4 \\
\hline 9 & 1 & $\mathrm{O} 29: \mathrm{H}+$ & 8 & 5 & 6 & 4 & 4 & 2 & 4 & 12 & 8 & 6 & 74 & 6 & 10 & 4 & 4 & 4 & 2 & 4 & 8 & 4 \\
\hline & 1 & O143:NM & 8 & 5 & 6 & 4 & 4 & 2 & 4 & 12 & 8 & 6 & 74 & 6 & 10 & 4 & 4 & 4 & 2 & 4 & 8 & 4 \\
\hline 10 & 1 & $0143: \mathrm{NM}$ & 8 & 5 & 6 & 4 & 4 & 2 & 4 & 12 & 8 & 6 & 74 & 6 & 10 & 4 & 4 & 4 & 2 & 4 & 8 & 2 \\
\hline 11 & 5 & O144:NM & 5 & 5 & 82 & 4 & 5 & 2 & 4 & 6 & 8 & 6 & 5 & 4 & 8 & 4 & 4 & 4 & 2 & 4 & 8 & 2 \\
\hline 12 & 1 & O136:NM & 5 & 5 & 6 & 4 & 5 & 2 & 4 & 6 & 8 & 6 & 0 & 0 & 8 & 4 & 4 & 4 & 2 & 4 & 8 & 2 \\
\hline 13 & 1 & O124:NM & 5 & 5 & 82 & 4 & 5 & 2 & 4 & 6 & 8 & 6 & 0 & 4 & 8 & 4 & 4 & 4 & 2 & 4 & 8 & 2 \\
\hline 14 & 13 & O28ac:NM & 5 & 5 & 6 & 4 & 5 & 2 & 4 & 62 & 6 & 6 & 9 & 4 & 8 & 4 & 4 & 4 & 1 & 4 & 8 & 2 \\
\hline 15 & 4 & O28ac:NM & 5 & 5 & 6 & 4 & 5 & 2 & 4 & 62 & 8 & 6 & 9 & 4 & 8 & 4 & 4 & 4 & 1 & 4 & 8 & 2 \\
\hline 15 & 1 & $\mathrm{O}: \mathrm{NM}$ & 5 & 5 & 6 & 4 & 5 & 2 & 4 & 62 & 8 & 6 & 9 & 4 & 8 & 4 & 4 & 4 & 1 & 0 & 8 & 2 \\
\hline 16 & 3 & O164:NM & 5 & 5 & 6 & 4 & 5 & 2 & 4 & 8 & 8 & 6 & 0 & 0 & 8 & 4 & 4 & 4 & 1 & 4 & 8 & 2 \\
\hline 17 & 11 & O136:NM & 5 & 5 & 6 & 4 & 5 & 2 & 4 & 6 & 8 & 6 & 8 & 4 & 8 & 4 & 4 & 4 & 1 & 4 & 8 & 2 \\
\hline 18 & 6 & $\mathrm{O} 29: \mathrm{NM}$ & 5 & 5 & 6 & 4 & 5 & 2 & 4 & 15 & 8 & 6 & 8 & 4 & 8 & 4 & 4 & 4 & 1 & 4 & 8 & 2 \\
\hline 19 & 6 & O143:NM & 5 & 5 & 6 & 4 & 4 & 2 & 4 & 8 & 6 & 6 & 8 & 6 & 4 & 4 & 4 & 4 & 2 & 4 & 8 & 2 \\
\hline 20 & 5 & O167:NM & 6 & 5 & 6 & 4 & 4 & 2 & 4 & 6 & 6 & 6 & 8 & 6 & 4 & 4 & 4 & 4 & 2 & 4 & 8 & 2 \\
\hline 21 & 1 & O136:H46 & 5 & 5 & 6 & 4 & 5 & 2 & 4 & 4 & 6 & 6 & 8 & 6 & 4 & 4 & 4 & 4 & 2 & 4 & 6 & 2 \\
\hline 22 & 8 & $\mathrm{O} 152: \mathrm{NM}$ & 5 & 2 & 6 & 4 & 5 & 2 & 4 & 6 & 6 & 6 & 12 & 6 & 8 & 4 & 4 & 4 & 2 & 4 & 8 & 2 \\
\hline 23 & 3 & $\mathrm{O} 135: \mathrm{NM}$ & 5 & 2 & 6 & 4 & 5 & 2 & 4 & 4 & 6 & 6 & 12 & 0 & 8 & 4 & 4 & 4 & 2 & 4 & 8 & 2 \\
\hline 24 & 3 & O152:NM & 5 & 2 & 6 & 4 & 5 & 2 & 4 & 6 & 6 & 6 & 12 & 6 & 10 & 4 & 4 & 4 & 2 & 4 & 8 & 2 \\
\hline 25 & 19 & O124:H30/NM & & 2 & 6 & 4 & 5 & 2 & 4 & 8 & 6 & 6 & 0 & 6 & 8 & 4 & 4 & 4 & 2 & 4 & 8 & 2 \\
\hline 26 & 1 & O164:NM & 5 & 2 & 7 & 4 & 5 & 2 & 4 & 8 & 6 & 6 & 8 & 6 & 8 & 2 & 4 & 4 & 2 & 4 & 8 & 2 \\
\hline 27 & 1 & O124:NM & 5 & 2 & 7 & 4 & 7 & 2 & 4 & 6 & 6 & 6 & 8 & 0 & 2 & 4 & 4 & 4 & 2 & 4 & 4 & 2 \\
\hline 28 & 1 & O124:H19 & 5 & 2 & 7 & 4 & 7 & 2 & 4 & 6 & 7 & 6 & 8 & 4 & 4 & 4 & 4 & 4 & 2 & 4 & 4 & 2 \\
\hline 29 & 1 & O143:H+ & 5 & 5 & 5 & 4 & 23 & 2 & 4 & 8 & 4 & 6 & 5 & 0 & 10 & 4 & 4 & 4 & 2 & 4 & 7 & 2 \\
\hline
\end{tabular}

PGI, glucosephosphate isomerase; IDH, isocitrate dehydrogenase; ACO, aconitase; G3P, glyceraldehyde-3-phosphate dehydrogenase; PE2, phenylalanyl-leucine peptidase; AK, adenylate kinase; MDH, malate dehydrogenase; PGD, gluconate-6-phosphate dehydrogenase; M1P, mannitol-1-phosphate dehydrogenase; GOT, aspartate aminotransferase; BGA, $\beta$-galactosidase; ADH, alcohol dehydrogenase; MPI, mannose-phosphate isomerase; G6P, glucose-6-phosphate dehydrogenase; IPO, indophenol oxidase; CAK, carbamate kinase; NSP, nucleoside phosphorylase; TDH, threonine dehydrogenase; SKD, shikimate dehydrogenase; GLU, glutamate dehydrogenase.

except for three isolates that expressed flagella antigen type $\mathrm{H} 30$.

\subsection{Genetic analysis of the population}

Genetic distance between each pair of the 29 ETs was estimated from the number of allelic differences and analyzed with the average linkage algorithm. The resulting dendrogram shows that EIEC strains fall into three distinct groups (labeled I-III) at a genetic distance greater than 0.05 (Fig. 1). Cluster I includes $78 \%$ of the non-invasive serotypes. Cluster II comprises the invasive serotypes $\mathrm{O} 28: \mathrm{H}^{-}$, $\mathrm{O} 29: \mathrm{H}^{-}, \quad \mathrm{O} 124: \mathrm{H}^{-}, \quad \mathrm{O} 136: \mathrm{H}^{-}, \quad \mathrm{O} 144: \mathrm{H}^{-}$and $\mathrm{O} 164: \mathrm{H}^{-}$. Cluster III comprises the invasive serotypes $\mathrm{O} 124: \mathrm{H}^{-}, \mathrm{O} 135: \mathrm{H}^{-}, \mathrm{O} 143: \mathrm{H}^{-}, \mathrm{O} 152: \mathrm{H}^{-}$, $\mathrm{O} 167: \mathrm{H}^{-}$. The serotypes $\mathrm{O} 124$ and $\mathrm{O} 164$ are included in the both clusters (Fig. 1), but the most of 
EIEC strains serotype $\mathrm{O} 124: \mathrm{H}^{-}$are in the cluster III $(95 \%)$ and the serotype $0164: \mathrm{H}^{-}$the most of them are in cluster II $(75 \%)$. Most of invasive strains belong to clusters II and III which included 45 (47\%) and $46(48 \%)$ of the total 96 invasive strains, respectively.

\section{Discussion}

Genetic analysis of the population of EIEC has shown most strains fall into two monophyletic clusters (II and III). This is inferred from genetic distances between chromosomal genotypes based on protein polymorphism detected by enzyme electrophoresis. The two EIEC clusters are not closely related to E. coli strains which possess other mechanism for causing diarrheal disease (data not shown).

The occurrence of the invasive ability in diverse backgrounds suggests that lateral transfer of plasmid-borne genes has been important in the evolution of this virulence phenotype [17]. Strains that lack the invasive phenotype, based on the Sereny test, and that are found within the clusters of invasive strains suggest a recent loss of the invasive property. The recent loss of the invasive phenotype could be due to either the loss or chromosomal integration of the invasive plasmid. Integration represses expression of invasion genes and may be advantageous when bacteria are outside of host cells or face adverse environmental conditions [18].

The present study showed 29 ETs, 19 of which included enteroinvasive $E$. coli strains. The similarity of ETs of EIEC strains having the same bioserotype, but varying in geographical origin. We observed that there was a high degree of divergence among invasive strains and non-invasive E. coli strains (Fig. 1). Most of the strains that did not belong to the major clusters II and III were negative for invasiveness were motile and decarboxylase lysine positive (Table 1). These results are in agreement with those found by Silva and co-workers. [10], who showed that invasive $E$. coli strains belong to bioserotypes that do not decarboxylate lysine and with a few exceptions, are not motile. Bando et al. [19] showed the same distinction between EIEC and non-EIEC strains by a genetic study based on random amplified polymorphic DNA (RAPD).

\section{Acknowledgments}

This work was supported by grants from FAPESP (94/3014-0).

\section{References}

[1] Fernandes, M.R. and Trabulsi, L.R. (1967) A new Escherichia coli serotype causing experimental keratoconjunctivitis in the guinea-pig (Culture 412 DEC-66). Preliminary report. Rev. Inst. Med. Trop. São Paulo 9, 62.

[2] Fernandes, M.R. and Trabulsi, L.R. (1969) Antigenic identity of culture 193T-64 and Escherichia coli O136:K78(B22). Rev. Inst. Med. Trop. São Paulo 11, 101-103.

[3] Formal, S.B. and Hornick, R.B. (1979) Invasive Escherichia coli. J. Infect. Dis. 137, 641-644.

[4] Gangarosa, E.J. (1978) Epidemiology of Escherichia coli in the United States. J. Infect. Dis. 137, 634-638.

[5] Levine, M.M. (1987) Escherichia coli that cause diarrhea: enterotoxigenic, enteropathogenic, enteroinvasive, enterohemorragic, and enteroadherent. J. Infect. Dis. 155, 377-389.

[6] Trabulsi, L.R., Fernandes, M.R. and Zuliani, M.E. (1967) Novas bactérias patogênicas para o intestino do homem. Rev. Inst. Med. Trop. São Paulo 9, 31-39.

[7] Ewing, W.H. (1986) Edwards and Ewing's identification of Enterobacteriaceae, 4th edn. Elsevier Science, New York, NY.

[8] Toledo, M.R.F. and Trabulsi, L.R. (1990) Frequency of enteroinvasive Escherichia coli in children with diarrhea and healthy controls in São Paulo, Brazil. Rev. Microbiol. São Paulo 21, 1-4.

[9] Echeverria, P., Sethabutr, O., Serichantalergs, O., Lexomboon, U. and Tamura, K. (1992) Shigella and enteroinvasive Escherichia coli infections in households of children with dysentery in Bangkok. J. Infect. Dis. 165, 144-147.

[10] Silva, R.M, Toledo, M.R.F. and Trabulsi, L.R. (1980) Biochemical and cultural characteristics of invasive Escherichia coli. J. Clin. Microbiol. 11, 441-444.

[11] Toledo, M.R.F. and Trabulsi, L.R. (1983) Correlation between biochemical and serological characteristics of Escherichia coli and results of the Serény test. J. Clin. Microbiol. 17, 419-421.

[12] Selander, R.K. and Musser, J.M. (1990) Population genetics of bacterial pathogenesis. In: The Bacteria, Vol. XI, pp. 1136. Academic Press, New York, NY.

[13] Serény, B. (1955) Experimental Shigella keratoconjunctivitis. A preliminary report. Acta. Microbiol. Acad. Sci. Hung. 2, 293-296.

[14] Selander, R.K., Caugantu, D.A., Ochman, H., Musser, J.M., Gilmour, M.H. and Whittam, T.S. (1986) Methods of multilocus enzyme electrophoresis for bacterial population genetics and systematics. Appl. Environ. Microbiol. 51, 873-884.

[15] Saitou, N. and Nei, M. (1987) The neighbor-joining method: a new method for reconstructing phylogenetic trees. Mol. Biol. Evol. 4, 406-425.

[16] Kumar, S., Tamura, K. and Nei, M. (1993) MEGA: molec- 
ular evolutionary genetics analysis, version 1.0. The Pennsylvania State University, University Park.

[17] Whittam, T.S., Wolfe, M.L., Wachsmuth, I.K., Orskov, F., Orskov, I. and Wilson, R.A. (1993) Clonal relationship among Escherichia coli strains that cause hemorraghic colitis and infantile diarrhea. Infect. Immun. 61, 1619-1629.

[18] Zagaglia, C., Casalino, M., Colonna, B., Conti, C., Calconi, A. and Nicoletti, M. (1991) Virulence plasmids of enteroinva- sive Escherichia coli and Shigella flexneri integrate into a specific site on the host chromosome: integration greatly reduces expression of plasmid-carried virulence genes. Infect. Immun. 59, 792-79.

[19] Bando, S.V., Valle, G.R.F., Martinez, M.B., Trabulsi, L.R. and Moreira-Filho, C.A. (1998) Characterization of enteroinvasive Escherichia coli and Shigella strains by RAPD analysis. FEMS Microbiol. Lett. 165, 159-165. 